\title{
Study and Construction of a small scale hybrid R.E.S Power System of Wind Generator and Photovoltaic
}

\section{Iakovos Yiakoumi}

Dip. Electrical \& Computer Engineer

(iakovos_yiakoumi@yahoo.com)

\section{Athanasios Safacas}

Professor Dr.-Ing., Electrical \& Computer Engineer

(a.n.safacas@ece.upatras.gr)

Laboratory of Electromechanical Energy Conversion, Electrical and Computer

Engineering Department, University of Patras, Greece

Abstract

In this project the design and implementation of an experimental, small scale hybrid system of produced electric energy is presented. Within this framework, a series of measurements was conducted, including meteorological measurements and measurements of produced power, separately for each of the sub-systems. After having that data processed, some techno-economic models were developed.

To accomplish the aim of monitoring the whole energy producing system, a special circuit that leads the data to a commercial data logger, either they are coming from the $\mathrm{W} / \mathrm{G}$ or the $\mathrm{P} / \mathrm{V}$, was built. Moreover, an independent control system was designed and implemented for the W/G, to achieve its protection in case of strong winds. There was also implemented an ohmic consumer, composed of a bank of glow-lamps to which the produced energy is driven.

The system is built up from a W/G of $1 \mathrm{~kW}$ power (Figure 1) and $4 \mathrm{P} / \mathrm{V}$ panels of $85 \mathrm{Wp}$ each, meaning that the total power is $340 \mathrm{Wp}$ (Figure 2).

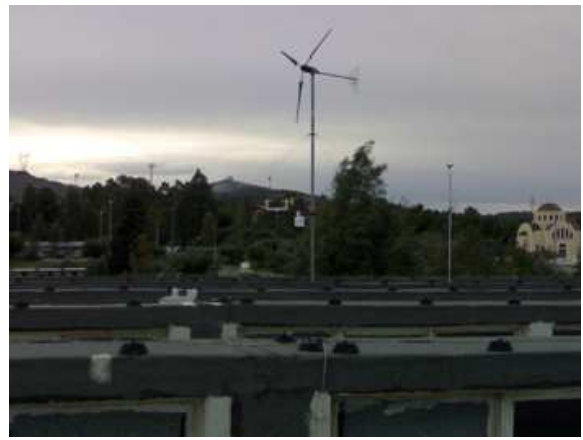

Fig. 1. W/G on the roof of L.E.M.E.C

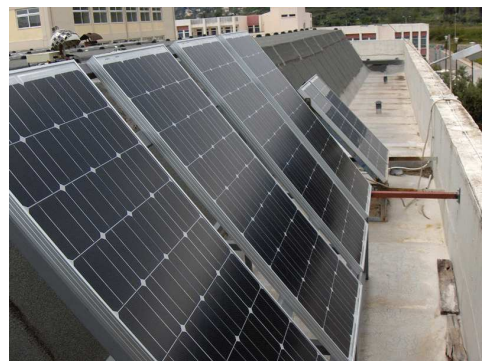

Fig. 2. P/V bank on the roof of L.E.M.E.C

\section{Introduction}

The hybrid system under study stores the produced energy in three lead - calcium - acid accumulators, connected in series with total voltage $36 \mathrm{~V}$. Each energy source $(W / G, P / V)$ is connected to the accumulators through charge regulators (Figure 3 ).

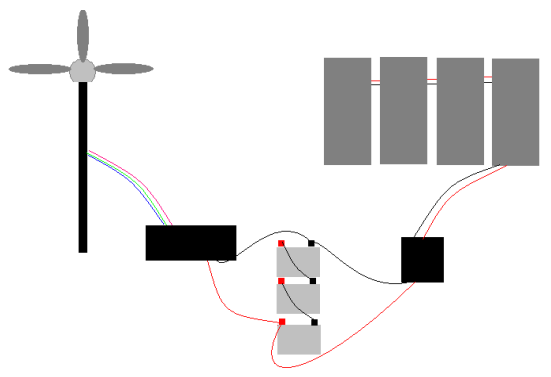

Fig. 3.Schematic representation of whole hybrid system

For experimental purposes, the charge regulators were disconnected, because when there are no accumulators 
connected to their endpoints, they do not operate. The resulting load was driven to a bank of glowlamps. Depending on the source under study and making use of a selective switch, the load was selected. When it comes to P/Vs $450 \mathrm{~W}$ lamps were used (Figure 4), and for the W/G lamps of 1275 W power were used (Figure 5).

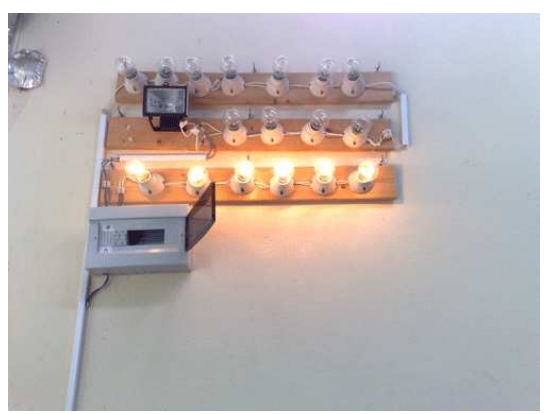

Fig. 4. The P/V load in operation

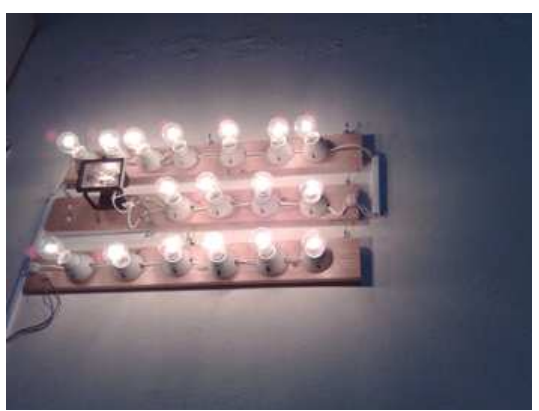

Fig. 5. The W/G load in operation

By measuring and storing the values of voltage and current, as well as of speed and direction of wind periodically, we were able to come into specific conclusions about every system respecting the following quantities:

Wind generator:

1. Power versus wind speed curve,

2. Average energy output from the $\mathrm{W} / \mathrm{G}$ during one year period,

3. Energy that the $W / G$ produces within a day,

4. Possibility of simultaneous operation of a hybrid system ,

5. Wind data of Patras University area.

$\mathrm{P} / \mathrm{V}$ module:

1. Average output energy of $P / V$ module during one year,

2. Instantaneous production power of $\mathrm{P} / \mathrm{V}$ module,
3. Study and comparison of produced energy in days with cloudiness and in sunny days.

The most essential questions that are raised and that there are being efforts to be answered in this project, is the verification with experimental results of how can a small hybrid system composed of W/G and P/V operate independently to sustain efficiently the electricity power of a house, or if it can give its energy to the greed. In what follows, it is being made a description of construction of an experimental system. Also experimental results are being presented.

\section{Technical specifications for the hybrid system}

The experimental hybrid system is built up from the following parts:

Wind Generator:

Table 1: Technical data about the W/G (Whisper 200)

\begin{tabular}{|l|l|}
\hline $\begin{array}{l}\text { Maximum power } \\
\text { output }\end{array}$ & $1000 \mathrm{~W}$ \\
\hline $\begin{array}{l}\text { Minimum rotation } \\
\text { velocity }\end{array}$ & $300 \mathrm{rpm}$ \\
\hline $\begin{array}{l}\text { Minimum wind } \\
\text { Velocity to start } \\
\text { rotation }\end{array}$ & $3.1 \mathrm{~m} / \mathrm{sec}$ \\
\hline Max rotation velocity & $1200 \mathrm{rpm}$ \\
\hline Optimal wind speed & $12.5 \mathrm{~m} / \mathrm{sec}$ \\
\hline Fin angle & $7 \mathrm{deg}$ \\
\hline Fins & $\begin{array}{l}3 \text { reinforced carbon } \\
\text { fibers }\end{array}$ \\
\hline $\begin{array}{l}\text { Mechanical } \\
\text { protection from high } \\
\text { wind speed }\end{array}$ & $\begin{array}{l}\text { Patented sidefurling } \\
\text { "stall method" }\end{array}$ \\
\hline Rotor diameter & $2.7 \mathrm{~m}$ \\
\hline $\begin{array}{l}\text { Maximum wind } \\
\text { speed for survivor }\end{array}$ & $55 \mathrm{~m} / \mathrm{sec}$ \\
\hline
\end{tabular}

The W/G uses a three-phase synchronous generator. Moreover, it is important to be noted that the W/G uses the stall method as a protection method by strong winds (Figure 6), as well as that the braking is achieved when we short the three endpoints of three-phase output (Figure 7). 


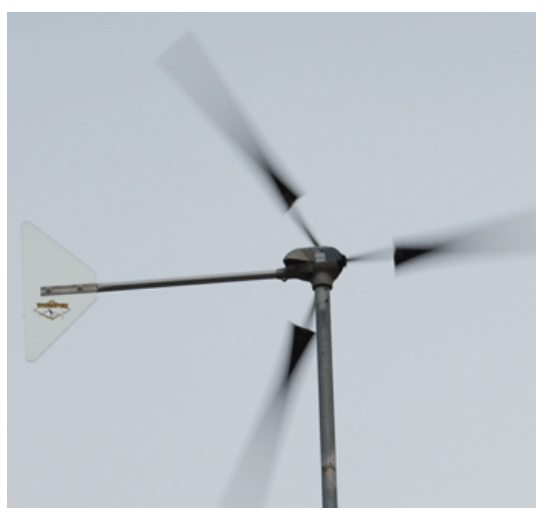

Fig. 6 . The «stall» method of protection

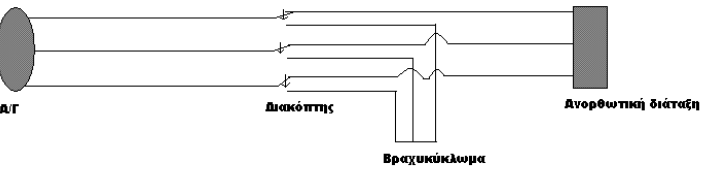

Fig. 7. Manual switch which shorts the output of W/G

In order to support the $\mathrm{P} / \mathrm{V}$ panels a metallic base was implemented, which has regulative bolts. The bolts allow the user, to change the horizontal angle of $P / V$ panels according to the season by changing their position. This is achieved when we follow the supportive method with change of horizontal axis angle every six months.

The two typical positions of collector are the following:

a) For the summer semester (21 March - 22 September), with angle $\beta=\left\{\varphi-\left(10^{\circ}\right.\right.$ to $\left.\left.15^{\circ}\right)\right\}$, (for the area of Patras at longitude $38.15^{\circ}$ we use slope between $\left.28.15^{\circ}-23.15^{\circ}\right)$.

b) For the winter semester (22 September - 21 March), with angle $\beta=\left\{\varphi+\left(10^{\circ}\right.\right.$ to $\left.\left.15^{\circ}\right)\right\}$, (for the area of Patras $\left.48.15^{\circ}-53.15^{\circ}\right)$.

Features of $\mathrm{P} / \mathrm{V}$ array:

The P/V panel consists of monocrystalline silicon cells.
Table 2 : Features of P/V array according to the technical sheet of constructor (Shell-Solar PowerMax ultra 85-P).

\begin{tabular}{|l|l|l|}
\hline Peak power [W] & Pmpp & $85 \mathrm{~W}$ \\
\hline Panel performance [\%] & $\eta$ & $13.4 \%$ \\
\hline $\begin{array}{l}\text { Peak operation voltage } \\
\text { [V] }\end{array}$ & Vmpp & $17.2 \mathrm{~V}$ \\
\hline $\begin{array}{l}\text { Peak operation current } \\
{[\mathrm{A}]}\end{array}$ & Impp & $4.95 \mathrm{~A}$ \\
\hline Open circuit voltage [V] & Vsc & $22.2 \mathrm{~V}$ \\
\hline Short circuit current [A] & Isc & $5.45 \mathrm{~A}$ \\
\hline $\begin{array}{l}\text { Minimum peak power } \\
\text { [W] }\end{array}$ & $\begin{array}{l}\text { Pmpp } \\
\text { min }\end{array}$ & $80.75 \mathrm{~W}$ \\
\hline $\begin{array}{l}\text { Series Fusing Current } \\
\text { [A] }\end{array}$ & Ifuse & $20 \mathrm{~A}$ \\
\hline
\end{tabular}

STC: The features above apply for vertical irradiance, $1000 \mathrm{~W} / \mathrm{m}^{2}$, spectrum AM 1.5 and cell temperature $25^{\circ} \mathrm{C}$.

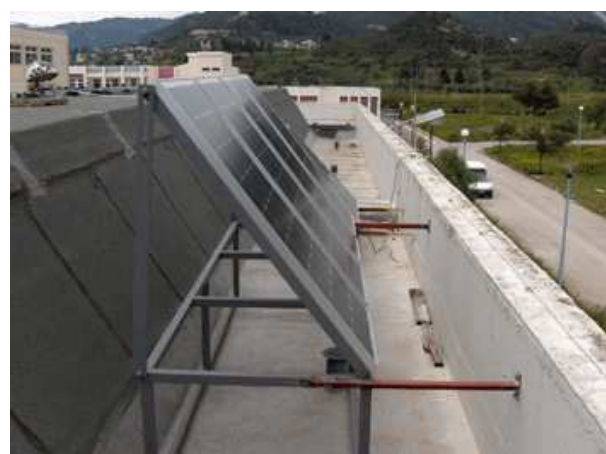

Fig. 8. Metallic base of PV-panels with a mechanism to change the slope, on the roof of L.E.M.E.C.

\section{Measuring device - Control - Construction}

For recording and storing the data related to the various physical quantities mentioned above, L.E.M.E.C obtained a data logger, which in addition to the pulsed inputs had also three analog inputs. Two of them were used for the storage of voltage and current data from the two systems. It should be mentioned that the data logger can only accept as input, D.C. voltage from 0 to $5 \mathrm{~V}$. Also, the additional pulsed inputs were used, to create a small scale meteorological station which records wind speed, wind direction, temperature and humidity in the greater area of Patras University.

As the storage device accepts direct voltage from 0-5 V and as it was desirable on the same circuit to have data entry from both power sources, it was important to achieve the two sources to have similar output for maximum voltage and maximum current. For this purpose one uncontrolled three phase bridge rectifier was used at the output of W/G (Figure 9). 


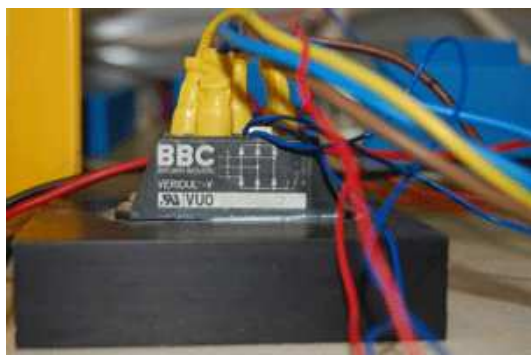

Fig. 9. Uncontrolled three phase bridge rectifier

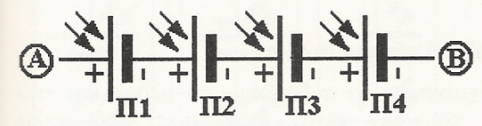

Fig. 10. $\mathrm{P} / \mathrm{V}$ series wiring

At the endpoints of $W / G$ a maximum voltage of $100 \mathrm{~V}$ was set from the control system and the four $P / V$ were connected at series connection in order to have maximum operation voltage $68,8 \mathrm{~V}$ (Figure 10).

To have the maximum import voltage of $5 \mathrm{~V}$, a voltage divider was implemented, so when the input voltage reached $100 \mathrm{~V}$, the output voltage (which is the input voltage of data logger) reach the maximum value of $5 \mathrm{~V}$. Several protective measures were taken, in order to avoid any over voltage at the side of data logger.

To measure the current the current measuring transducer LAH-25 was used at a suitable connection that can measure $25 \mathrm{~A}$. The current from the $W / G$ does not exceed the $12 \mathrm{~A}$, whereas the respective current at the $P / V s$ is $5 \mathrm{~A}$.

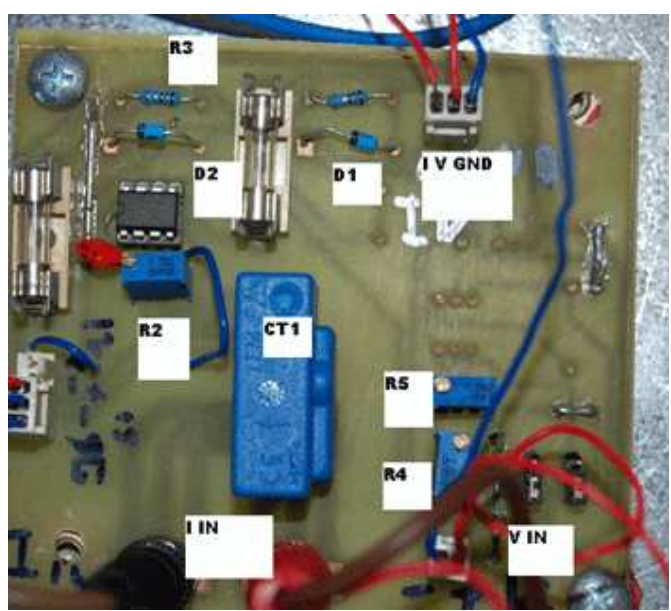

Fig. 11. Circuit board for the data input of current and voltage

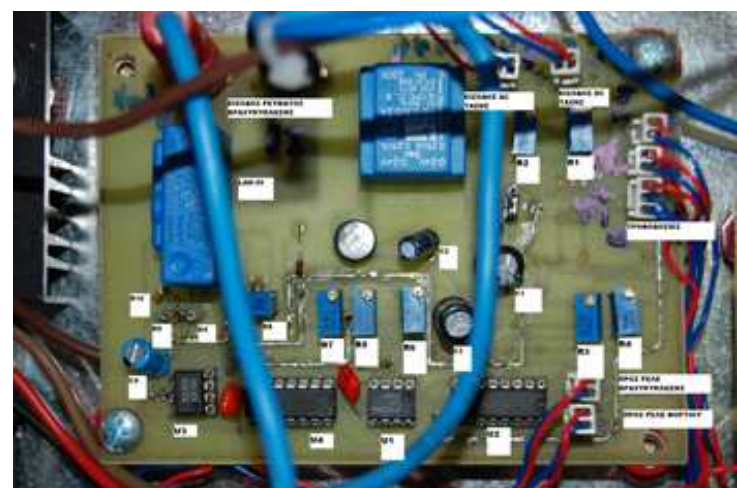

Fig. 12. Total control circuit board of the W/G

It wasn't possible to take measurements and store data from the $W / G$, unless the factory control system was removed because the factory control system needed to give its load only to bateries. After removing the factory control system, a new control system was designed and implemented, so that the W/G would be protected in case of high speed winds. Moreover, in the same circuit a coupling - decoupling load device was also implemented to eliminate the difficulties in the starting procedure from the W/G due to inactivity.

To avoid great values of r.p.m. that extends a critical value, the A.C. voltage at the endpoints of two of the W/G phases (line to line voltage) and also the current resulting after the short circuit of the three phases where monitored.

The signal from the polar voltage is needed to get informed if the r.p.m. of the W/G has increased into forbidden levels. The signal from the short circuit current is needed to get informed if the r.p.m. of the W/G has decreased and consequently the resulting torque of the wind towards the W/G after the break was activated. In case of an error occurring part of the control circuit or whole of it being destroyed, or in case of disruption of the electrical supply at circuits, specific measures have been taken, in order to break the W/G automatically. This way, the destruction of the W/G is prevented. For the circuit coupling-decoupling the resulting voltage of the reconstructive device was used, which is degraded with a voltage divider. After the degradation the signal is being driven to an operational amplifier, where it is being compared to a reference voltage. When the reference voltage is exceeded, the load is connected to the W/G. In case of disruption of the electrical supply at circuits, the load is connected permanently at the W/G, working indirectly as a break (action-reaction).

\section{Experimental results}

One of the objectives of this project was to conduct various measurements of as much duration as possible for each system separately. The first experiment was 
conducted for the determination of the curve load of one photovoltaic panel.

Figure 13 presents the graphic representation of one PV panel loading a variable ohmic load at the endpoints.

Figure 14 presents the graphic representation of power to voltage of $1 \mathrm{P} / \mathrm{V}$. Maximum power point which is known as the "knee point" is obvious.

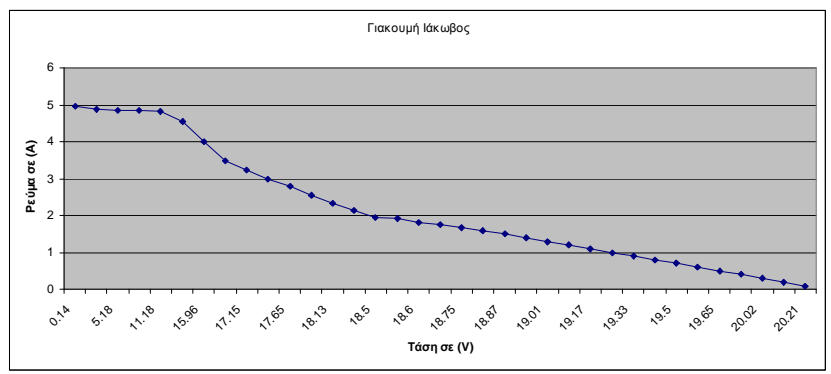

Fig.13. Current to voltage relation of one $\mathrm{P} / \mathrm{V}$ (21/11/07 13:50)

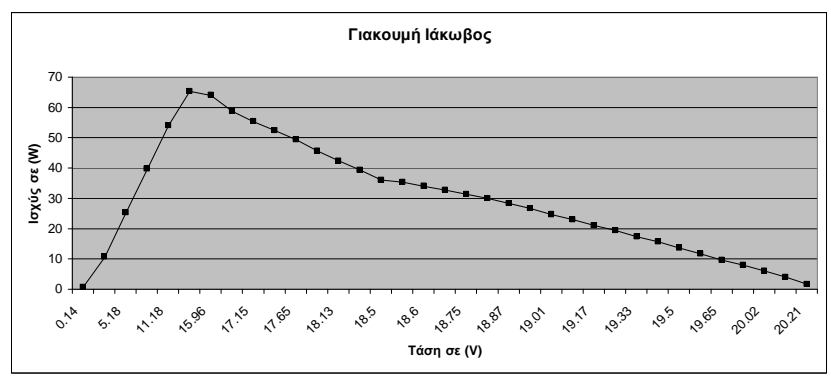

Fig.14. Power to voltage relation of one $\mathrm{P} / \mathrm{V}$ (21/11/07 13:50)

The second experiment was about the acquisition of loading curve in relation to the speed of the wind for W/G.

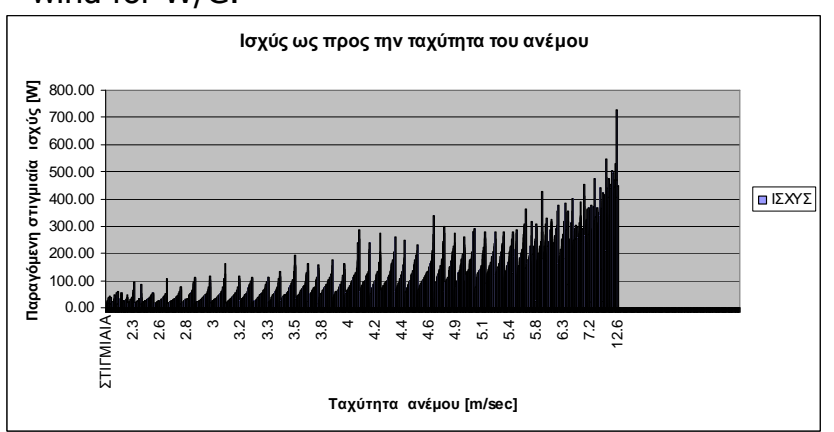

Fig.15. Power in relation to the speed of wind in W/G under experimentation

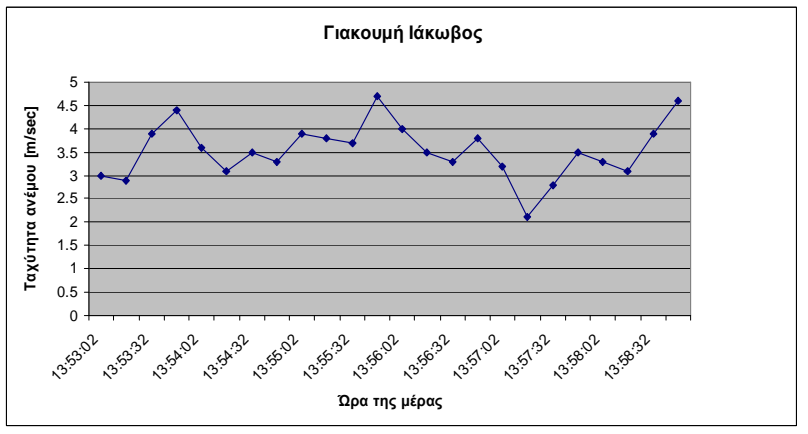

Fig.16. Graph presents the movement of instant wind speed in a small time period of 5 minutes, every 15 seconds (16.12.08)

Graph 15 presents the produced instant power in relation to the speed of the wind. For safety reasons, the control system of the W/G was regulated to break the W/G when the wind speed exceeds the value of 17 $\mathrm{m} / \mathrm{sec}$. The maximum produced instant power was 725 $\mathrm{W}$ and it was observed when the speed of the wind was $12.1 \mathrm{~m} / \mathrm{sec}$. Subsequently, the system continued to operate and record measurements of the wind speed within a month so as to record wind data of Patras University area.

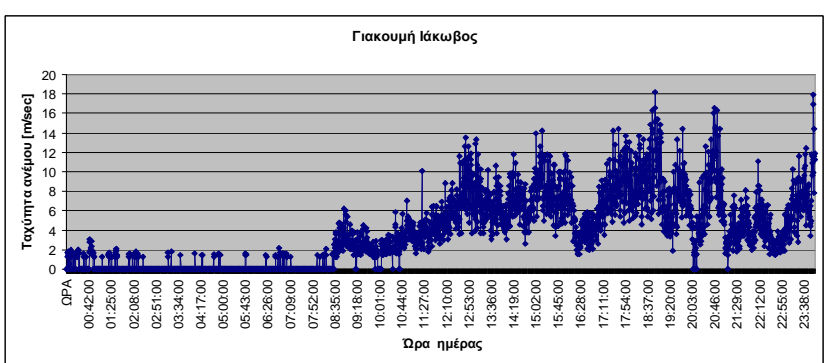

Fig.17. Instant wind speed of wind in relation to time of the day.(28.11.08).

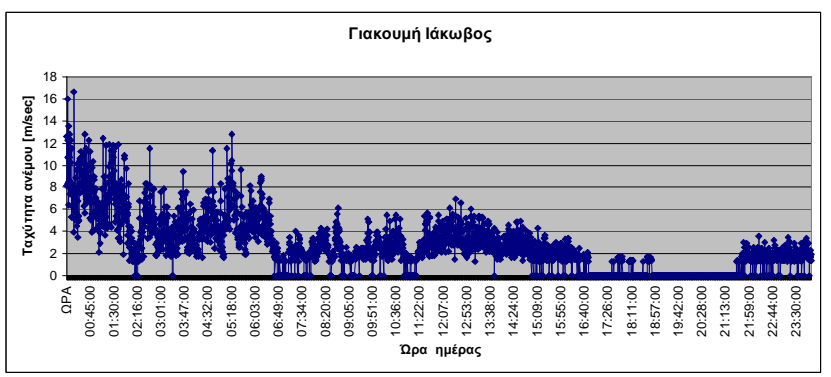

Fig.18. Instant wind speed of wind in relation to time of the day (29.11.08).

It is to be highlighted that the series control of the W/G implemented for this project was put into operation in days with high wind speed and was successfully operated, avoiding destruction of the system. The two previous graphs presents the wind speed in relation to 
the time of each day. In order to be more consistent, the measurements were taken in consequent days. Subsequently, for one month the $\mathrm{P} / \mathrm{V}$-system was put into operation and from the measurements, the following graphs arise.

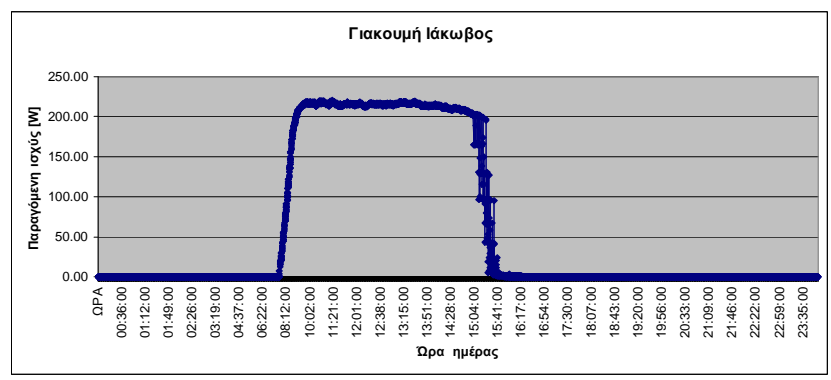

Fig. 19. Production of $P / V$-system in a sunny day 23/10/08

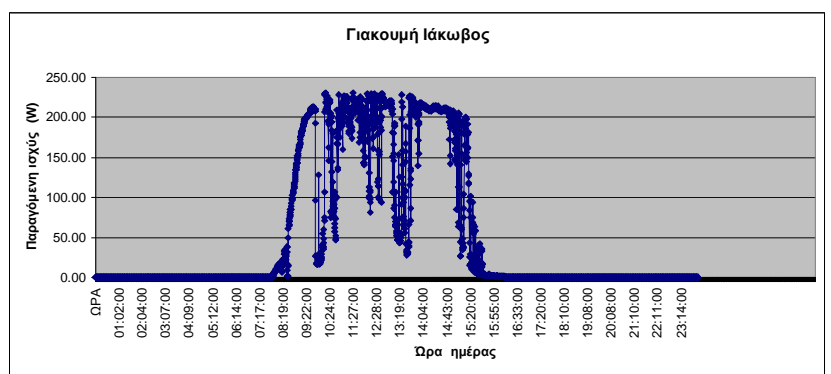

Fig. 20. Production of $\mathrm{P} / \mathrm{V}$-system in a slightly cloudy day $26 / 10 / 08$

On $23 / 10 / 08$, that was a sunny day, the total production of the P/V system was 1393.7 Wh, while the maximum instantaneous power was $240.3 \mathrm{~W}$.

On $26 / 10 / 08$, that was a slightly cloudy day, the total production of energy was $929.1 \mathrm{Wh}$, while the maximum instantaneous power was $230.8 \mathrm{~W}$.

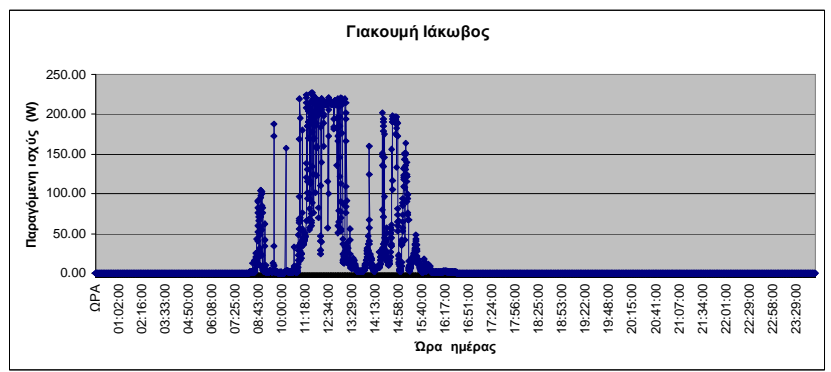

Fig. 20. Production of $P / V$-system in a cloudy day $30 / 10 / 08$

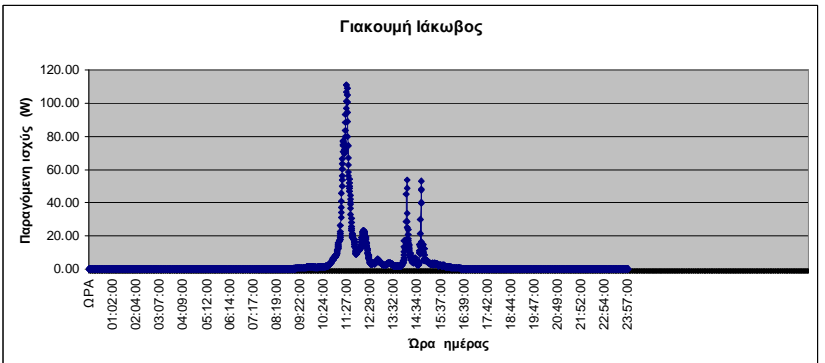

Fig. 21. Production of P/V-system in a very cloudy day $8 / 11 / 08$

On $30 / 10 / 08$, a cloudy day, the total production of energy was only $304.5 \mathrm{Wh}$, while the maximum instantaneous power was $227.2 \mathrm{~W}$. On $8 / 11 / 08$, a very cloudy day, the total production of energy was only 69.9 Wh, while the maximum power was $116.2 \mathrm{~W}$. (all graphs were made in Excel spread sheets.)

\section{Techno-economic models}

Suggested models:

\section{Greece}

1) Deposit of 600,000 euro in a Bank at interest rate of $6 \%$ and construction of $100 \mathrm{kWp} \mathrm{P/V}$ station for a period of 20 and 30 years period.

2) Deposit of 150,000 euro in a Bank at interest rate of $6 \%$ and construction of a $100 \mathrm{kWp} P / \mathrm{V}$ station for 20 years.

3) Determination of an amount (total investment in a bank net of funding), which a business man would be benefit from his investment if his fund returned to him more money than an investment in a bank would.

\section{Cyprus}

1) Deposit of 120,000 euro in a Bank at interest rate of $7 \%$ and construction of $20 \mathrm{kWp} \mathrm{P/V} \mathrm{station} \mathrm{for} \mathrm{a} \mathrm{period}$ of 20 and 30 years.

2) Installation of the $P / V$ system with $55 \%$ of its finable construction cost funded and reduced funding of produced $\mathrm{kWh}$. In this model there is a comparison of the deposit of the investment amount (54,000 euro) in a Bank with the interest of $7 \%$ with the investment in a 20 $\mathrm{kWp} \mathrm{P} / \mathrm{V}$ station.

3) In this model is deemed that the construction of the $\mathrm{P} / \mathrm{V}$ station, the total amount of money is loaned from a bank the first time with a high interest rate loan and in the second time with a low interest rate loan. This model also has one other separation. The first part deems that 120,000 euros borrowed with high funding price of the produced kWh and the second part deems that the funding received concerns only the acquisition 
of equipment (55\%) and a loan of 54,000 euro are assigned.

\section{Conclusions}

In order to obtain adequate, valid and trustworthy data of the wind power and of the amount of energy produced by an experimental hybrid system the recording system should operate continually at least for one year, The following conclusions are extracted:

1. There is a huge and trustworthy production of energy from the $\mathrm{P} / \mathrm{V}$ panels even in case of cloudiness.

2. Aiolic print of University of Patras area is good enough to support a small scale W/G.

3. Figures 21 and 22 and the quantity amounts reveille that the use of wind and solar energy may result to the implementation of a hybrid system near the area of Patras University. Figures 22 and 23 show that the two R.E.S. power sources complete each other.

The following graphs (fig.22, fig.23) refer to the wind and solar energy at 5/11/08 for the under study area of Patras University.

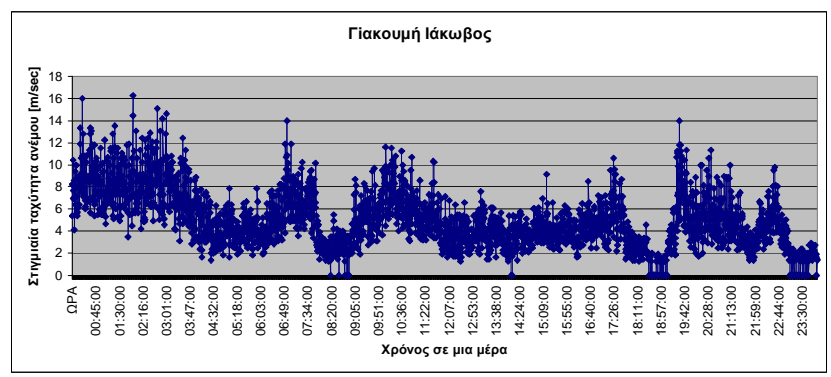

Fig. 22. Wind speed as function of the time

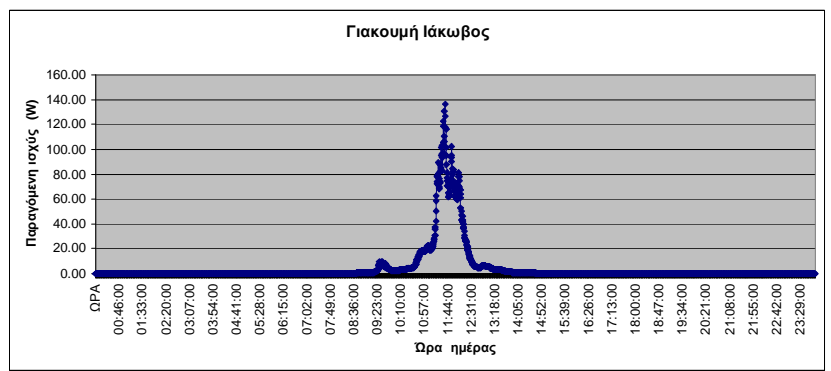

Fig. 23. Total power production $102.6 \mathrm{Wh}$ (maximum instantaneous power $139.2 \mathrm{~W}$ ) capital on a P/V station of total power $100 \mathrm{~kW}$ in Greece was studied. The economotechnic data for the P/V station in Greece were obtained from the web-site of Greek Association for Photovoltaic. The reason that the specific data were used is that they are close enough with our experimental results. For the calculation of the capital return, excel formulas were used. The techno economic data lead to the conclusion that, under the existing legislation is better to invest on a $\mathrm{P} / \mathrm{V}$ station than investing to a bank at interest of $6 \%$, because by the end of the 20 year period the profit from the $\mathrm{P} / \mathrm{V}$ station will be 100,000 euro more than if the money were invest in the bank.

5. The intention of investment and return of a capital amount in a P/V station of $20 \mathrm{kWp}$ station in Cyprus was also studied under this project. Again for this examination data from the Greek Association for Photovoltaic model were used, but this time was modified according the conditions in Cyprus.

6. Comparing the meteorological conditions of Cyprus and Greece, it was ascertained that in areas of Cyprus which have the same geographical latitude with areas of Greece, there is up to $18 \%$ more sunshine than Greece during the year.

\section{Bibliography}

(1) Yiakoumi, I. « Study and construction of a small scale hybrid R.E.S. system», diploma thesis Electrical and Computer Engineering department, University of Patras ,Greece, 2009.

(2) Fragkiadakis, I. E., «PV systems», Thessalonica: Ziti, 2007.

(3) Bergeles. G., «Wind generators» Athens: Simeon, 2005.

(4) http://www.helapco.gr/

(5) http://www.cres.gr/kape/index_gr.htm,

(6) www.ieee.org

(7) A. Safacas: ' 'Electrical Machines I,II ' ' ,University of Patras ,Greece, 2002

(8) A. Safacas: ' 'Power Electronics ' ', University of Patras ,Greece, 2004

(9) Kadelis: ' 'Wind Generators and Wind Power' ' Athens 2005

4. With in this project the intention of investment and return of the investment 